MIDAS

Museus e estudos interdisciplinares

$10 \mid 2019$

Varia

\title{
Patrícia Roque Martins - Museus (In)Capacitantes: Deficiência, Acessibilidades e Inclusão em Museus de Arte
}

\section{Viviane Panelli Sarraf}

\section{(2) OpenEdition \\ Journals}

\section{Edição electrónica}

URL: http://journals.openedition.org/midas/1566

DOI: $10.4000 /$ midas. 1566

ISSN: 2182-9543

\section{Editora:}

Alice Semedo, Paulo Simões Rodrigues, Pedro Casaleiro, Raquel Henriques da Silva, Ana Carvalho

\section{Refêrencia eletrónica}

Viviane Panelli Sarraf, «Patrícia Roque Martins - Museus (In)Capacitantes: Deficiência, Acessibilidades e Inclusão em Museus de Arte », MIDAS [Online], 10 | 2019, posto online no dia 31 maio 2019, consultado no dia 24 setembro 2020. URL : http://journals.openedition.org/midas/1566 ; DOI : https://doi.org/ $10.4000 /$ midas. 1566

Este documento foi criado de forma automática no dia 24 setembro 2020.

\section{(c) (1) (-)}

Midas is licensed under a Creative Commons Attribution-NonCommercial-ShareAlike 3.0 International License 


\title{
Patrícia Roque Martins - Museus (In)Capacitantes: Deficiência, Acessibilidades e Inclusão em Museus de Arte
}

\author{
Viviane Panelli Sarraf
}

\section{REFERÊNCIA}

Martins, Patrícia Roque. 2017. Museus (In)Capacitantes: Deficiência, Acessibilidades e Inclusão em Museus de Arte. Vol. 7. Coleção Estudos de Museus. Casal de Cambra: Caleidoscópio e Direção-Geral do Património Cultural. 367 páginas, ISBN 978-989-658-468-9.

1 O livro Museus (In)Capacitantes: Deficiência, Acessibilidades e Inclusão em Museus de Arte da Coleção Estudos de Museus, publicado em 2017, é fruto da tese de doutoramento homónima de Patrícia Roque Martins apresentada à Faculdade de Belas-Artes da Universidade de Lisboa em 2014.

2 Mesmo sendo o resultado de uma tese de doutoramento, o livro não apresenta um registo excessivamente académico. O engajamento e a seriedade da pesquisa desenvolvida ficam evidentes ao longo da leitura dos capítulos. Além disso, a linguagem utilizada é dinâmica e os dados apresentados são facilmente compreendidos por estarem devidamente analisados e fundamentados ao longo do texto.

3 A publicação apresenta grande qualidade técnica e uma escrita instigante, deixando evidente que a autora não mediu esforços para apresentar e analisar criticamente o tema da inclusão de pessoas com deficiência e as acessibilidades em museus de arte no âmbito da realidade portuguesa, mas incluindo também referências a casos exemplares ocorridos nos Estados Unidos, no Brasil, no Reino Unido, em França e em Espanha. 
O tema é de grande relevância para os debates atuais das áreas da museologia, da educação, da ação e mediação cultural e das acessibilidades, constituindo um desafio na gestão das instituições museológicas, quer em Portugal, quer noutras geografias. Em Portugal, disso é sintomático a realização da $4 .^{a}$ edição do Congresso de Educação $e$ Acessibilidade em Museus e Património Cultural ocorrido em Lisboa e na Batalha, no ano de 2017. As três primeiras edições deste evento ocorreram em diferentes regiões da Espanha, e têm sido eventos relevantes para ampliar as discussões sobre a temática.

o livro encontra-se dividido em duas partes, uma destinada a discutir o tema «Os Museus e a Deficiência/Incapacidade: Que Relações e Impactos» e a segunda centra-se em «Estudos de Caso: Estratégias Inclusivas aplicadas no Museu Calouste Gunbenkian Coleção do Fundador e Coleção Moderna.

6 A primeira parte engloba dois capítulos. O primeiro capítulo «A Deficiência/ Incapacidade: Para uma Abordagem Social da Diversidade» apresenta informações atualizadas sobre o estatuto social e cultural da pessoa com deficiência em Portugal e a respetiva legislação que defende os seus direitos à educação, ao trabalho, à assistência, à cultura e à mobilidade urbana. O segundo capítulo «Os Museus e a Deficiência/ Incapacidade sob o Signo Social» analisa criticamente as ações culturais do universo museológico internacional em benefício da inclusão dos públicos com deficiência e da acessibilidades estendida a outros públicos.

7 A segunda parte, mais extensa, engloba três capítulos com enfoque na apresentação e análise de experiências de ações educativas e culturais inclusivas realizadas pela autora no Museu Calouste Gulbenkian com a participação de grupos de visitantes com diferentes deficiências. Consideramos que este é um ponto alto na obra, uma vez que a autora compartilha com o leitor os desafios inerentes ao desenvolvimento de propostas de atividades acessíveis em museus, apresentando com modéstia e fidedignidade os resultados das experiências realizadas. No primeiro capítulo «A fruição e a Prática por Parte das Pessoas com Deficiência Intelectual - "Estou a adorar a minha vida!"» a autora apresenta, discute e reflete sobre a ação educativa inclusiva destinada ao público com deficiência intelectual nas oficinas intituladas "Museu Aberto" junto à exposição de longa duração Museu Calouste Gulbenkian - Coleção Moderna.

No segundo capítulo «A Fruição Prática por Parte de Pessoas com Deficiência Visual. "(Ir ao museu) fez-me lembrar quando ainda via..."» abordam-se os resultados de um estudo de caso centrado na realização de visitas com materiais e estratégias sensoriais na exposição de longa duração do Museu Calouste Gulbenkian - Coleção Moderna. A proposta, destinada ao público com deficiência visual, foi desenvolvida em parceria com um grupo de pessoas cegas da Fundação Raquel e Martin Sain, uma organização que trabalha em prol da educação e do direito ao trabalho de pessoas com deficiência visual em Portugal.

9 Por fim, o terceiro capítulo «A Fruição e a Prática por parte de Pessoas Surdas. "Acham que eu sou deficiente?"» refere-se a um estudo de caso com pessoas surdas. Apresenta a aproximação da autora com a comunidade surda por meio da realização de um curso básico de Língua Gestual Portuguesa e o processo de desenvolvimento da proposta de visita com um grupo de pessoas surdas mediada por um profissional surdo, realizada em reuniões conjuntas entre a pesquisadora, a Associação Portuguesa de Surdos (APS) e representantes da área de mediação do Museu Calouste Gulbenkian - Coleção do Fundador. Por fim, apresenta e discute os resultados da ação, tendo em consideração as demandas culturais da comunidade de pessoas surdas em Portugal. 
10 Nas «Conclusões», Patrícia Roque Martins propõe uma reflexão em busca de caminhos para um "museu capacitante" que tenha nas suas ações e políticas o reconhecimento e o respeito da dimensão da diversidade dos seus públicos e a garantia dos direitos culturais das pessoas com deficiência no ambiente cultural.

11 A divisão proposta mostra ao leitor que há dois enfoques complementares na publicação: a apresentação de informações, referências teóricas e empíricas acerca da inclusão de pessoas com deficiência em museus e na sociedade como um todo; e a análise dos resultados que integraram a pesquisa de doutoramento da autora e que agora são passíveis de reflexão e multiplicação por meio do acesso a este livro.

12 A autora usa, entre as suas referências, os principais e mais atuais teóricos, advindos de diferentes escolas e nacionalidades, oferecendo ao leitor um panorama dos estudos e das pesquisas da área da acessibilidade em museus, inclusão social, educação inclusiva, estudos culturais e estudos da deficiência. Alguns dos autores citados para referenciar as suas reflexões são reconhecidos internacionalmente, como por exemplo: Richard Sandell, Eilean Hooper-Greenhill, Ralph W. Smith, Janice Majewski, Jocelyn Dodd e Nina Simon. Também são referenciadas pesquisas correlatas de autores portugueses, brasileiros, entre outros, como Clara Mineiro, Viviane Panelli Sarraf, Amanda Tojal, Begoña Consuegra Cano e Virgínia Kastrup. Neste enquadramento, a autora referencia ainda manuais técnicos de diversas instituições museológicas e culturais que se tem dedicado a publicar orientações para o desenvolvimento de ações de inclusão em museus e espaços culturais, tais como a Smithsonian Institution, a American Association of Museums e a Art Beyond Sight, nos Estados Unidos, a Direção Geral de Património Cultural, em Portugal, a Museums and Galleries Comission, no Reino Unido, ou o Conselho Internacional de Museus (ICOM), entre outros.

13 Para além da revisão bibliográfica e das citações que embasam as suas análises críticas, a autora apresenta reflexões próprias advindas das propostas empíricas apresentadas e problematizadas na sua pesquisa. Os relatos das experiências empíricas realizados pela autora em parceria com o Museu Calouste Gulbenkian - Coleção do Fundador e Coleção Moderna e com instituições que trabalham com pessoas com deficiência de Portugal merecem um destaque especial, uma vez que configuram situações reais criadas pela autora, com objetivos científicos, que resultaram em reflexões e na apresentação de resultados compartilhados com as instituições envolvidas e com os leitores.

14 Este tipo de abordagem acrescenta um caráter de fidedignidade e concretização das proposições, dos conceitos apresentados e defendidos na argumentação, mostrando caminhos a seguir e desdobramentos possíveis para pesquisas e experiências congéneres, inspirando novas proposições e o desenvolvimento desta área.

15 A partir da análise do livro podemos afirmar que é uma publicação de referência para profissionais, investigadores e estudantes da área de museologia, das artes, da cultura e do turismo engajados com a inclusão e com os direitos culturais das pessoas com deficiência. 


\section{AUTORES}

\section{VIVIANE PANELLI SARRAF}

Instituto de Estudos Brasileiros da Universidade de São Paulo, Brasil, vsarraf@gmail.com 